\title{
Radioisotope therapy of bone metastases
}

Maciej Bączyk

Department of Nuclear Medicine, Heliodor Święcicki Hospital, Medical University, Poznań, Poland

[Received 3 VIII 2011; Accepted 16 XI 2011]

\section{Abstract}

Radionuclide therapy has been an integral part of systemic treatment of patients with advanced and disseminated cancer for 50 years. Specific radioisotopes ( $\beta$ - or $\alpha$-emitters) with selective concentration at sites of bone cancer damage are used in the treatment. Radioisotopes are an important addition to the armamentarium of clinicians who take care of patients with advanced cancer and painful cancer bone metastases (especially osteoblastic and mixed type). They offer a high degree of efficacy with minimal toxicity and simple administration, fulfilling the fundamental criteria for palliative treatment that should combine minimal patient discomfort and toxicity with maximal clinical effect.

Key words: radioisotopes, bone metastases, therapy of pain

Nuclear Med Rev 2011; 14, 2: 96-104

\section{Introduction}

Due to constantly increasing neoplastic disease incidence, bone metastases are becoming a more and more serious issue in oncology. As regards the most common tumours, half of them are connected with a high probability of developing metastases to the skeletal system. Bones, next to lungs and liver, are among the top three sites of distant metastases localization. Neoplasms that give metastases to the skeletal system are most frequently cancers of the prostate, breast, kidneys, lungs, and thyroid (Table I).

These metastases are located mainly in the so-called cancellous bones that have good vascularization connected with a large

Correspondence to: Maciej Bączyk, MD, PhD

Department of Nuclear Medicine, Heliodor Święcicki Hospital

Medical University

ul. Przybyszewskiego 49, 60-355 Poznań, Poland

Tel: +48618691765

e-mail: endopoz@onet.pl amount of active haematopoietic marrow. This is enhanced by slower blood flow through sinusoid vessels [1]. The scheme of bone metastasis formation is presented in Figure 1 [2].

Bone matrix remodelling occurs as a consequence of neoplastic cell presence. In healthy bone the balance between processes of ossification and resorption is maintained. They always take place in one way that is genetically programmed and modified by particular external and internal factors. A fundamental role in bone

Table 1. Frequency of advanced stage bone metastases

\begin{tabular}{lc}
\hline Primary lesion & Frequency of bone metastases occurrence \\
\hline Prostate & $70-80 \%$ \\
Breast & $73 \%$ \\
Thyroid & $42 \%$ \\
Lungs & $36 \%$ \\
Kidneys & $35 \%$ \\
Digestive tract & $5 \%$ \\
\hline
\end{tabular}

\section{Bone metastasis}

Infiltrate of lymphatic or blood vessel walls through primary tumour

$\downarrow$

Dissemination of neoplastic cells to the bloodstream

$\downarrow$

Neoplastic cell colonization in bone marrow

\section{$\downarrow$}

Neoplastic cell extravasation:

adherence to endothelium $\rightarrow$ endothelium spasm $\rightarrow$ adherence to basement membrane $\rightarrow$ basement membrane dissolution $\rightarrow$ neoplastic cell movement to marrow stroma (enhancing factors: large spaces between endothelium cells, fragmentary lack of basement membrane in sinusoid vessels of bone marrow, chemotactic effect of some substances that occur neutrally in bone tissue, e.g. type I collagen, growth factors)

$\downarrow$

Bone infiltrate with modification of the surroundings $\downarrow$

Damage to old and/or formation of new bone tissue

Figure 1. Scheme of bone metastasis formation. 
remodelling processes is played by two types of cell that have different functions and origins: osteogenic cells - osteoblasts, and resorption cells - osteoclasts.

Osteoblasts have an approximate life time of 3 months and come from mesenchymoma multipotential matrix cells. They produce type I collagen and proteoglycans that form the organic intracellular structure of the bone which is further calcified. Osteoblasts are also responsible for synthesis of osteonectin, osteopontin, osteocalcin, and various types of proteinase $[3,4]$.

Osteoclasts, the life time of which amounts to approximately 2 weeks, come from a monocyte-macrofagal line of haematopoietic cells that, after differentiation, connect and build active polynucleated forms. Large amounts of carbonic anhydrase in osteoclast enable separation of $\mathrm{H}^{+}$from $\mathrm{H}_{2} \mathrm{CO}_{3}$ and then its removal directly to the surrounding bone, which initiates the osteolysis process. Osteoclasts have the ability to phagocytise bone and then digest it within its cytoplasm. An important factor for osteoclast function is negative feedback in which apoptosis inducing factors are organic bone matrix degradation products. The products of bone matrix degradation as well as local growth factors (bone morphogenetic protein - BMP), transforming growth factor $\beta$ (TGF $\beta$ ), and fibroblast growth factor (FGF) stimulate osteoblast precursor cells for maturation. Osteoprotegerin (OPG) produced by these cells is the main inhibitor of osteoblast maturation and belongs to the RANK/RANKL/OPG system which plays a fundamental role in bone remodelling processes $[5,6]$.

\section{Classifications and consequences of bone metastases}

The most common localization of metastatic lesions is often connected with the site of primary focus and anatomic conditions - direct vascular connections between the main vein systems, portal vein, and pulmonary vein with spinal veins cause frequent metastases to the spine in the course of prostatic and breast cancer. Tumour dissemination to bones typically has a multi-focus nature.

Table 2 presents the most common localization of metastatic lesions out of $100 \%$ of patients with diagnosed metastases according to different data [7-10].

A few classifications of stage progress in bone neoplastic dissemination can be found. In orthopaedics, the most commonly used classification is the one by Yamashita presented in Table 3 [11].

As regards nuclear medicine, the Solovay scale or Bone Scan Index (BSI) are used much more frequently [12-15].

The general condition of a patient with bone metastases is typically connected not with the presence of metastases but rather with
Table 2. The most common localization of bone metastatic lesions

\begin{tabular}{ll}
\hline $\begin{array}{l}\text { The most common } \\
\text { metastasis localization }\end{array}$ & Lesion percentage (\%) \\
\hline Lumbar spine & $65-72$ \\
Sacral spine & $65-68$ \\
Pelvis & $60-66$ \\
Ribs & $50-62$ \\
Cranial bones & $35-44$ \\
Femora & $30-44$ \\
Cervical and thoracic spine & $25-40$ \\
\hline
\end{tabular}

its consequences - the so-called skeletal-related events (SRE). The latter can be divided into: directly induced by the presence of neoplastic cells in bone (CIBD - cancer-induced bone disease) and related to loss of bone mass as a result of treatment (CTIBL - cancer treatment-induced bone loss), e.g. in antiandrogenic therapy of prostatic cancer. Another significant parameter is the period of time until the moment of occurrence of the first serious bone event — the time to a skeletal-related event (TTSRE) [1].

The most common SREs are: pathologic fracture of vertebrae or other bones (up to $25 \%$ ), spinal cord compression (up to $8 \%$ ), hypercalcaemia (up to $25 \%$ ), and necessary surgical treatment (up to $4 \%$ ) or radiotherapy (up to $33 \%$ ) due to clinical symptoms $[1,16,17]$.

However, the presence of bone metastases typically causes pain that occurs in over $70 \%$ of patients. Bone tissue has rich neuration, mainly from the periosteum, but as it has been recently found that the endings of nerve fibres also reach the medullary cavities in long bones (medullary membrane) and parts of cancellous bones [18]

Pain pathogenesis in metastasis has not been fully understood and in most cases has multiple causes. However, it seems that the following factors are the most significant $[18,19]$ :

A. Mechanical factors that stimulate bone nociceptors:

- compression connected with bone remodelling and periosteum damage;

— increased pressure inside bone;

- bone deformation due to osteolysis;

- direct compression of metastatic tissue on nerves or surrounding soft tissue;

- pathologic fractures that change bone compression distribution (e.g. vertebra compression fractures).

B. Chemical mediators influencing nociceptors:

- mediators activated or produced by neoplasm (e.g. TGF, TNF, IL);

- activation of arachidonic acid cascade (prostaglandin E)

C. Other factors:

Table 3. Yamashita classification

\begin{tabular}{lccc}
\hline $\begin{array}{l}\text { Progression } \\
\text { stadium }\end{array}$ & $\begin{array}{c}\text { Central skeleton } \\
\text { (lumbar and thoracic spine, ribs) }\end{array}$ & $\begin{array}{c}\text { Medial skeleton } \\
\text { (pelvis, cranium, cervical spine) }\end{array}$ & $\begin{array}{c}\text { Peripheral skeleton } \\
\text { (sternum, scapulae, femoral and humeral bones) }\end{array}$ \\
\hline Stadium I & Yes & No & No \\
Stadium II & Yes & Yes \\
Stadium III & Yes & Yes & Yes \\
\hline
\end{tabular}


- disturbances in blood supply and outflow.

Symptoms related to bone metastases cause considerable deterioration of the life quality and health condition of the patients and also shorten their life in a statistically significant way.

Bone metastases diagnostics is based on taking history, clinical examination, imaging studies, and biochemical tests. A thorough history completed by a clinical examination allows determination of the location of painful metastatic lesions in $90 \%$ of cases. It also allows for the establishment of the nociceptive nature of the pain which in almost $70 \%$ of cases accompanies neuropathic pain.

\section{Bone metastatic lesion imaging and determination of bone remodelling type}

In imaging diagnostics of bone metastases, plain X-ray of a particular skeletal element is used as well as computed tomography $(\mathrm{CT})$, magnetic resonance (MRI), positron emission tomography (PET), and tests with the use of nuclear medicine techniques (SPECT planar scintigraphy). Basic radiologic classification of bone metastases differentiates osteolytic and osteoblastic types. In practice, bone metastases are never of uniform nature. It is more accurate to describe them as metastases with a dominant osteolytic process and a dominant process of osteosclerosis, while in the case of no dominance - mixed metastases (osteolytic-osteoblastic) (Table 4) [1, 20].

Determination of bone remodelling type is extremely significant in making decisions connected with patient qualification for

Table 4. Most commonly observed variants of bone metastases depending on primary focus site

\begin{tabular}{lc}
\hline Primary focus & Metastases properties \\
\hline Prostate & $\begin{array}{c}\text { Osteoblastic (75\%) mixed } \\
\text { and osteolytic (25\%) } \\
\text { Osteolytic (65\%) mixed } \\
\text { and osteoblastic (35\%) }\end{array}$ \\
Breast & Osteolytic \\
$\begin{array}{l}\text { Lung, kidney, pancreas, } \\
\text { oesophagus, melanoma }\end{array}$ & Osteoblastic/mixed \\
Stomach & Osteolytic/mixed/osteoblastic \\
\hline
\end{tabular}

metastases treatment. Bone metastases from various organs are different in terms of their effect on osteoclast and osteoblast function. Increased pathologic stimulation of an osteoclast leads to intensification of osteolysis with concurrent tendency for hypercalcaemia. Increased osteoblast stimulation causes overproduction of bone matrix with secondary hypercalcification and is very rarely accompanied by a tendency for hypercalcaemia. In these patients calcium concentration is much more frequently close to the lower limit and is accompanied by increased levels of alkaline phosphatase. However, both described situations occur at the same time in a large group of patients (Figure 2) [7-10, 21].

Plain radiograms have considerably low sensitivity in detecting early changes in bone matrix density caused by the presence of neoplastic cells. In the past, limit values of detecting metastatic focus in X-rays were lesions with a diameter over $10 \mathrm{~mm}$ and change in bone matrix density of $40-50 \%$ compared with surrounding healthy tissue. Currently, as X-ray apparatus have increasingly better quality (digital techniques) which allows a precise computer analysis of the obtained image, detection sensitivity is evidently rising. It is extremely important from a clinical standpoint as in the case of prostatic cancer approximately $40 \%$ of spine metastases is detected during pain syndrome diagnostics treatment based on initial diagnosis of degenerative spinal disease [22].

Currently, computed tomography seems to be a sufficient study for clear diagnosis of bone metastases. It allows, especially with the use of multi-row detector $\mathrm{CT}$, precise evaluation of both the extent and nature of the lesion. In exceptional cases, most commonly of single lesions, the necessity of additional differential diagnostics between neoplastic and inflammatory osteolysis or neoplastic and degenerative osteosclerotic process might arise.

Magnetic resonance, similarly to CT, shows high sensitivity (over 70\%) and specificity (almost 100\%) in detecting metastatic lesions and allows for differentiation of osteoblastic and osteolytic foci. Low focus intensity in T1 weighted time, and increased in T2 weighted, suggests osteolysis, while reduction of signal in $\mathrm{T} 1$ and T2 weighted indicates osteoblastic nature of metastasis. Whole body MRI (MR-WBS) in T1 and T2 weighted sequences, including STIR, with application of paramagnetic contract appears to be particularly useful - sensitivity over $90 \%$. Apart from revealing bone metastases, it also allows for evaluation of neoplasm invasiveness in bone marrow [23].

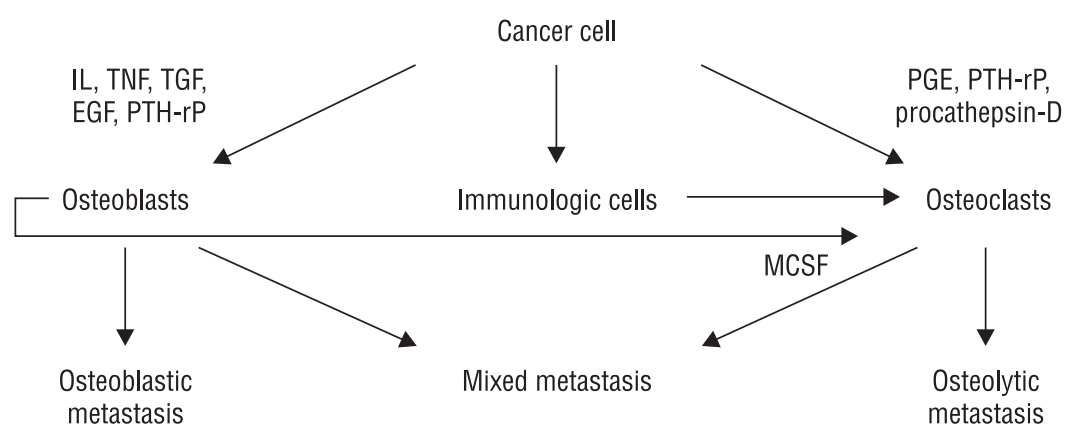

Figure 2. Mechanisms inducing bone remodelling in bone metastatic focus. IL — interleukin; TNF — tumor necrosis factor; TGF — tumor growth factor; EGF — epidermal growth factor; PTH-rP — parathyroid hormone-related protein; PGE — prostaglandin E; MCSF — macrophage colony-stimulating factor. 
PET study is not a target method for bone metastases diagnostics (due to economically unfavourable ratio of test effectiveness to test cost). Also, in order to obtain the best diagnostic outcomes, 18-NaF ought to be applied (high affinity to hydroxyapatite) and not 18-fluorodezoxyglucose (18-FDG), which is a typical metabolic tracer and provides a number of additional diagnostic data in most neoplastic patients [24].

Commonly used PET-CT with 18-FDG in the case of high differentiation of neoplastic cells, low metabolism of primary lesion and metastatic lesions might give false negative results, especially in skeletal system foci.

Currently, the fundamental study in bone metastases diagnostics is still scintigraphy. In the skeletal system this study confirms neoplastic dissemination to bone but also provides additional data on the extent and localization of the lesions. Scintigraphy sensitivity in detecting metastatic lesions might even be a few times higher compared to plain X-ray. It detects foci of abnormal bone metabolism (mainly neoplastic metastases) even of 1-2 mm in size and bone matrix density change of approximately $10 \%$. Unfortunately, scintigraphy clearly loses its value compared to MR-WBS [25-28]. However, scintigraphy sensitivity might be increased from $70 \%$ to over $80 \%$ by using SPECT technique. A further considerable increase in sensitivity is possible by conducting studies with SPECT-CT. Introduction of new informatics technology, which has been suggested by recent reports, might increase scintigraphy sensitivity to as much as $89 \%[29,30]$. According to many opinions, no dominance of the MR-WBS method over classic scintigraphy can be found in clinical practice. Both studies performed concurrently complete each other perfectly. Low specificity remains a crucial issue in scintigraphy. Routinely applied carriers in isotopic diagnostics are ${ }^{99 \mathrm{~m} T c}$ labelled phosphonate compounds (the most commonly used is methylene diphosphonate - MDP) which accumulate in all the sites of increased bone metabolism within a newly-formed bone due to chemiabsorption and phosphonate complex exchange. In certain cases, only a thorough history and the said additional imaging tests are sufficient to differentiate potentially metastatic lesions with post-trauma, inflammatory, and necrotic lesions. Based on scintigraphic study (in contrast to the imaging studies described above) it is not possible to clearly determine the type of metastasis and fracture presence.

A number of cases in bone metastases diagnostics require "overlaying" diagnostic images with the use of at least two techniques. In clinical practice it is recommended to combine isotopic studies and radiology (X-ray, CT, MRI), which is partly possible due to modern gamma cameras. This is critical in the case of qualification for isotopic treatment — foci lesions, like bone metastases that are not always visible in MRI or CT, must intensely accumulate phosphonate derivatives used in diagnostic and therapeutic isotope techniques (Figure 3). This works the other way round as well - intense accumulation of MDP-TC ${ }^{99 m}$ in scintigraphy that qualifies patients for treatment does not exclude the presence of unstable pathologic fractures or a large lytic focus which carries the risk of fracture and requires urgent orthopaedic and neurosurgical attendance in the first place (Figures 4-6).

Biochemical diagnostics of bone metastases has been the subject of numerous discussions on the possibilities of using bone turnover markers in oncology. The American Society of Clinical Oncology suggests labelling calcium concentration and potential

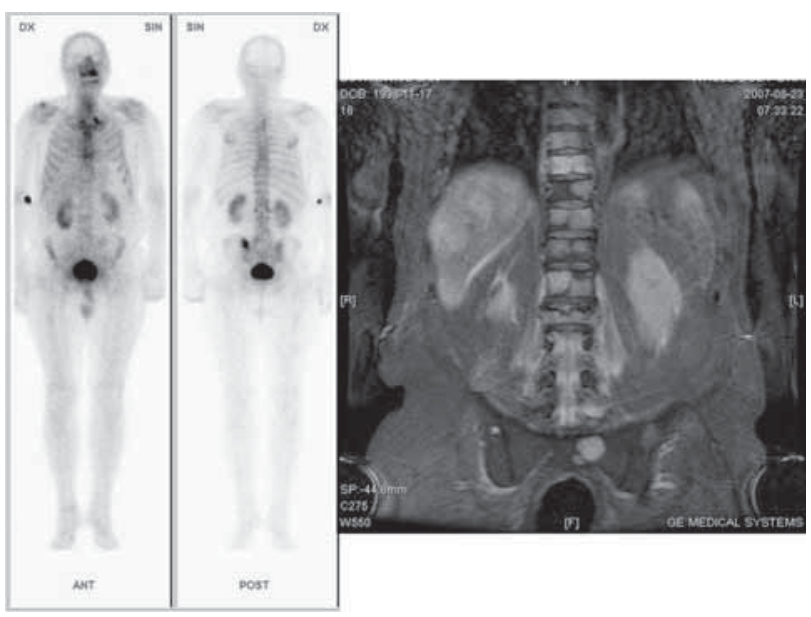

Figure 3. Disseminated metastatic lesions in the bone with pathologic vertebra fracture clearly visible only in MRI (70-year-old man with palatine tonsil cancer and prostate cancer).

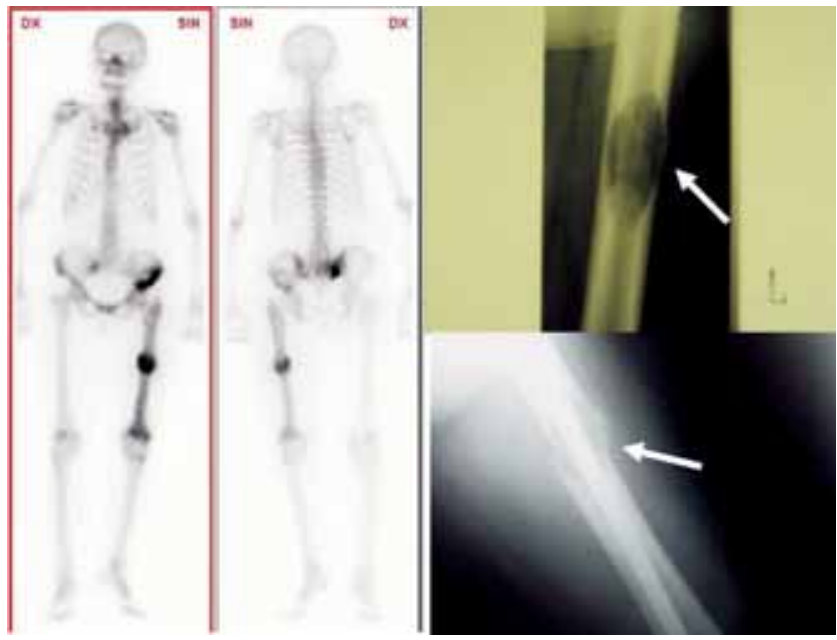

Figure 4. Osteolytic lesions in the femur with subsequent pathologic fracture in a 67-year-old woman with kidney cancer.

bone alkaline phosphatase (BALP) and also indicates that routine labelling of bone turnover markers in monitoring the course of treatment should not be recommended, despite its usefulness in certain cases [31-33].

To conclude all the above data, the following course of action might be suggested in cases of suspected bone metastasis in order to chose proper treatment, including isotopic therapy:

1. Confirmation of the presence and stage of metastases (bone scintigraphy, X-ray, CT, MRI, PET).

2. Evaluation of bone metastasis nature - osteolytic, osteosclerotic, or mixed (typically in the case of larger foci X-ray is sufficient) and exclusion of the presence of especially unstable pathologic fractures as well as evaluation of potential risk of spinal core compression.

3. Hypercalcaemia risk evaluation (calcium concentration in blood serum, localization of primary focus - the highest risk of hypercalcaemia occurs in cancer of the lungs, breast, and kidney as well as myeloma). 


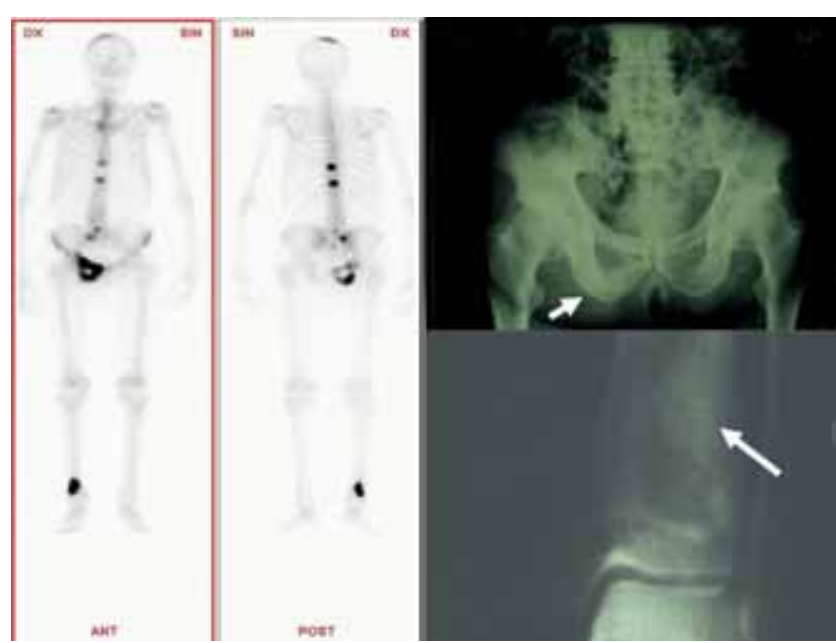

Figure 5. Osteosclerotic lesions in the pelvis and tibia in an 82-year-old man with prostate cancer.
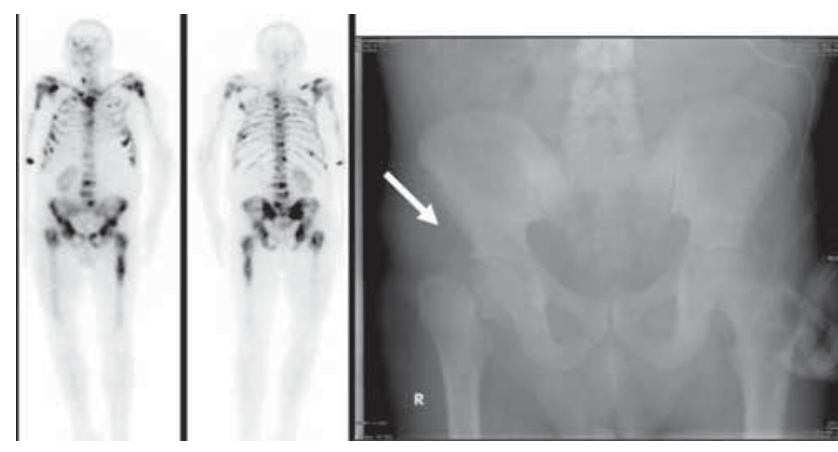

Figure 6. Pathologic fracture of the right femur revealed in X-ray during qualification for radioisotope therapy (65-year-old patient with prostate cancer).

4. Aspirative biopsy in the case of difficulties with determining primary focus.

\section{Treatment possibilities in bone metastases}

Forms of therapy used in bone metastases treatment are presented in Figure 7. Possibilities of combining isotopic therapy with other treatment methods will be discussed further in the work.

\section{Radioisotope application in the treatment of bone metastases}

The destruction of at least some neoplastic cells in bone metastatic foci due to ionizing radiation causes a considerable decrease in local release of both inflammatory and pain reaction mediators. Concurrently, metastatic mass is reduced, which leads to a decrease in mechanical stimulation of pain receptors. Treatment with radioactive isotopes is more and more frequently used in early stages of bone metastases therapy. It is supposed to prevent development of pain symptoms and other complications. In Poland, two isotopes are currently applied in bone metastases isotopic therapy: strontium-89 (Sr $\left.{ }^{89}\right)$ and samarium-153

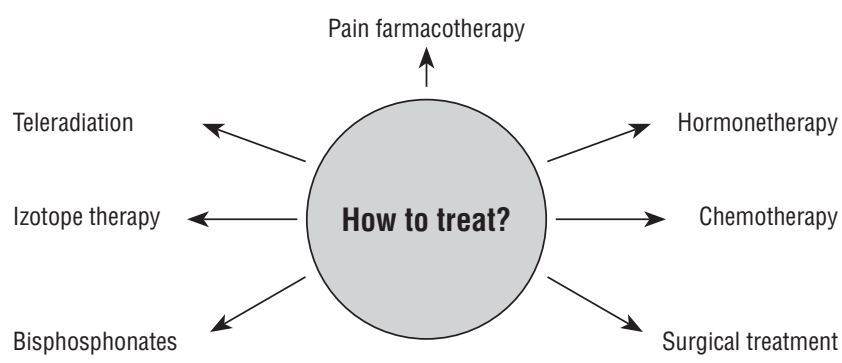

Figure 7. Forms of therapy applied in bone metastatic lesions.

$\left(\mathrm{Sm}^{153}\right)$ instead of previously used phosphorus $32\left(\mathrm{P}^{32}\right)$ [34-37]. Emitters of $\alpha$ radiation (mainly radium -223 ) are still examined in clinical trials $[38,39]$.

\section{Strontium-89}

Strontium-89 is a pure $\beta$ radiation emitter and calcium analog. It is uptaken and incorporated into collagen in all the sites of increased bone remodelling, with pathologically stimulated osteoblast, which is typical mainly of osteosclerotic foci of bone metastases. The biological half-life of $\mathrm{Sr}^{89}$ isotope amounts to 50.5 days. Therefore, doses might be small as the therapeutic effect will last long after incorporation into osteoblastic focus. The drug is administered intravenously (like strontium chloride), while the main means of isotope elimination are the kidneys (up to 90\%).

\section{Samarium-153}

Samarium-153 is applied intravenously in the form of chelate compound with tetraphosphonate (Lexidronian), which determines the high sensitivity and specificity of drug accumulation in sites of bone remodelling (high affinity to hydroxyapatite) caused by the presence of neoplastic cells. Sm ${ }^{153}$ emits $\beta$ therapeutic radiation and low-energy $\gamma$ radiation, which allows post-therapeutic images to be obtained with the use of gamma cameras. $\mathrm{Sm}^{153}$ half-life period amounts to 1.9 days, which determines the necessity of applying high activities yet makes this treatment similar to classic teleradiotherapy (large dose in a short time) — it is sufficient for a therapeutic effect that the radioisotope bonds with hydroxyapatite for a short time. The main path of eliminating the isotope that is not bonded by bone tissue are the kidneys, as in the case of $\mathrm{Sr}^{89}$.

\section{Rules of qualification for metastases treatment with the use of radioisotopes}

Qualification for isotope therapy includes the following factors is listed below.

\section{Nature of metastasis}

Principally, osteoblastic or mixed metastases are an indication for radioisotope therapy; osteolytic metastases require bisphosphonate treatment in the first place.

The mechanisms of radioisotope bonding in metastatic foci described above cause similar $\mathrm{Sr}^{89}$ and $\mathrm{Sm}^{153}$ effectiveness in osteoblastic bone metastases (approximately $75-80 \%$ positive response to monotherapy). In the case of $\mathrm{Sm}^{153}$, a lytic osteoblastic lesion with a large amount of hydroxyapatite bonds the therapeutic complex well. In the case of $\mathrm{Sr}^{89}$ therapy, high osteoblast 
activity allows for incorporation of a large amount of isotope into pathologically changed osteosclerotic bone matrix. The effectiveness of mixed metastases therapy decreases in inverse proportion to the increase in osteolytic component, especially in large foci (analgesic effect in monotherapy decreases to 20-40\%). Based on numerous reports it can be assumed that it is the type and size of metastasis, and secondly neoplasm type, that dictate therapy effectiveness. Reports on good treatment effectiveness refer not only to prostate and breast cancer patients but also to individuals with cancer of the kidney, urinary bladder, and lungs as well as osteosarcoma [38-42].

\section{Intensity, localization, size, and number of tracer accumulation foci in bone scintigraphy}

The multi-focus nature of metastatic lesions is one of the basic indications for radioisotope treatment. Quantitative measurement of skeletal system involvement might be performed by the above-mentioned Solovay scale or BSI calculation. The more intense the radiotracer accumulation and the smaller the focus, the better the treatment effectiveness expected. The presence or high risk of pathologic fractures, particularly in the spine, indices of mechanical compression of nerve roots or vertebral cord constitute a contraindication for radioisotope therapy. The patient might be qualified for isotope treatment again following interventional orthopaedic procedure, interventional radiotherapy, or intensive intravenous bisphosphonate therapy. Patients with bone metastases and superscan scintigram might be problematic. The author's own observations suggest a good expected effect of the treatment, yet the risk of serious haematological complications amounts to approximately $50 \%$, which indicates the need for care in calculating the dose - reduction by at least $25 \%$ is recommended $[40,41]$.

\section{Patient general condition and life expectancy}

It is generally acknowledged that life expectancy in a patient qualified for radioisotope therapy should not be shorter than 2-3 months. Poor general condition and considerable cachexia might also be direct causes of patient disqualification from the treatment. The first pain symptoms occur approximately after 7-14 days following dose administration and can be observed for as long as a year [43-46].

\section{Bone marrow damage indices}

Characteristics of bone marrow damage $(\mathrm{E}<3.0 \mathrm{~T} / \mathrm{l}$ $\mathrm{Hb}<10 \mathrm{~g} \%, \mathrm{~L}<3.000 \mathrm{G} / \mathrm{l}$ - recommended smear for determining absolute granulocyte number, which should not be lower than $1.500 \mathrm{G} / \mathrm{l} ; \mathrm{PLT}<100.000-60.000 \mathrm{G} / \mathrm{l})$ that might be directly connected with neoplastic disease or previous treatment (e.g aggressive chemotherapy or radiotherapy) might disqualify the patient from the treatment. Administration of radioisotope dose to patients with bone marrow damage carries a risk of full-blown thrombocytopaenia, leucopoenia or anaemia [10, 34, 36, 37].

\section{Renal failure and urine retention or urine incontinence}

A lack of possibilities to eliminate a radioisotope from patient's body might lead to drug accumulation and an increase in potential side effects. Also, infection of potential catheters, urine bags, nephrofixes, etc. applied in patients with retention or incon- tinence constitute a significant problem. Although, this issue is not an absolute contraindication for radioisotope therapy in ambulatory conditions of drug administration, it is connected with high risk of contamination persons who take direct care of the patient $[47,48]$.

\section{Parameters of calcium-phosphorus metabolism}

Every bone metastases patient requires regular check of calcium concentration in blood serum. Patients that take calcium preparations (for different indications) should discontinue about 10 days prior to scheduled strontium isotope treatment (potential uptake competitiveness). Failure in meeting this requirement might considerably reduce $\mathrm{Sr}^{89}$ uptake by bone metastases foci and thus significantly decrease treatment effectiveness. In the case of patients qualified for $\mathrm{Sm}^{153}$ therapy it is recommended to discontinue bisphosphonate administration for a period of 2-4 weeks (potential impediment of $\mathrm{Sm}^{153}$ tetraphosphonate uptake). However, in 2008 and 2009 Lam published two works connected with prostate cancer patients. The author showed that zolendronate, similarly to pamidronate, does not decrease uptake of samarium ${ }^{153} \mathrm{Sm}$ isotope. The treatment had high effectiveness and significantly low toxicity $[49,50]$.

\section{Other forms of parallel oncologic and symptomatic therapy}

Most types of chemotherapy, due to potential myelotoxic effect, might block radioisotopic treatment. According to many reports, it is possible to conduct parallel local radiotherapy from external sources before and during isotopic treatment (potential strengthening effect). Radioisotopic treatment might be a continuation of radiotherapy in the case of exceeding the upper dose absorbed from external sources or risk of local complications of local radiotherapy. The pros and cons of combining radioisotopic therapy with other forms of oncologic treatment are presented in Table 5 [51-56]

No clear interactions between concurrent application of bisphosphonate and $\mathrm{Sr}^{89}$ have been observed (different uptake point in the bone). Moreover, bisphosphonate administration prior to $\mathrm{Sr}^{89}$ injections might have a beneficial impeding effect on osteoclast activity and allow for osteoblast dominance, which increases the possibility of greater radiopharmaceutical accumulation in the metastatic focus. Bisphosphonate administration directly after radioisotope injection practically eliminates the risk of hypercalcaemia development (15\%) as a consequence of radiopharmaceutical administration. No reports on $\mathrm{Sm}^{153}$ isotope interactions with calcium preparations can be found. As mentioned above, in patients treated with $\mathrm{Sm}^{153}$ it is recommended to withdraw bisphosphonate prepa-

Table 5. Pros and cons of combining isotope therapy with other treatment forms

\begin{tabular}{|c|c|c|}
\hline Isotope therapy & $\begin{array}{l}\text { Effectiveness } \\
\text { increase }\end{array}$ & $\begin{array}{c}\text { Risk of undesirable } \\
\text { effects }\end{array}$ \\
\hline With radiotherapy & High & Moderately increased \\
\hline With bisphosphonates & High $* * /$ moderate & Low \\
\hline With chemotherapy & High $^{\star *} /$ moderate & $\mathrm{High}^{\star \star \star}$ \\
\hline With hormone therapy & High/moderate & Low \\
\hline
\end{tabular}

*depends on total absorbed dose; **especially in breast cancer; $\star * *$ depends on chemotherapy type 
rations for 2-4 weeks prior to scheduled isotope treatment. Their administration on the third day following the treatment is believed to be beneficial. Similarly to Sr89 therapy, the risk of post-therapeutic hypercalcaemia is almost absolutely eliminated. This scheme of combining $\mathrm{Sr}^{153}$ therapy with bisphosphonates is particularly recommended in patients with metastases that show osteolytic component and hypocalcaemic tendency [57-60].

\section{Radioisotope choice}

As mentioned above, both $\mathrm{Sm}^{153}$ and $\mathrm{Sr}^{89}$ have similar effectiveness in osteoblastic bone metastases treatment. In the case of mixed metastases the therapy effectiveness decreases, especially with $\mathrm{Sr}^{89}$. Thus, such patients should be prescribed $\mathrm{Sm}^{153}$ isotope therapy. The reason is the disproportion of osteoblast and osteoclast activity in mixed metastases, especially with the dominance of osteolysis. The possibility of fast incorporation and longer "maintenance" of $\mathrm{Sr}{ }^{89}$ isotope is considerably reduced, which leads to a decrease in absorbed therapeutic dose and final therapeutic effect. Higher effectiveness of $\mathrm{Sm}^{153}$ is probably a result of less specific mechanism of bonding therapeutic complex to hydroxyapatite - a large dose of a radiopharmaceutical will always give at least a partially therapeutic effect even when it is bonded to a lesser extent and for a short time $[21,43,44,57,58,61]$. According to observations, Sr ${ }^{89}$ isotope has slightly higher and often delayed myelotoxicity, especially in younger individuals and multiple therapies. Some observations indicate that every subsequent therapeutic dose administered might give a long lasting effect of decreasing blood platelet and leukocyte concentrations by a subsequent $10 \%$ compared to initial values. The impact on the red blood cell system is approximately $50 \%$ smaller. As regards the percentage of early clinically significant yet typically mild and spontaneously subsiding haematological complications, it is quite similar for both isotopes and amounts to approximately $25 \%$, which is confirmed by literature reports. The risk of their occurrence not only rises proportionally with each subsequent dose administered but it is also a result of previously (or simultaneously) applied treatment, e.g. radiotherapy, chemotherapy, or hormone therapy, as well as symptomatic analgesic treatment. The analgesic effect of $\mathrm{Sm}^{153}$ occurs slightly sooner than in the case of $\mathrm{Sr}^{89}$. However, some authors claim that it is also shorter and requires more frequent treatment renewal $[7,10,34,36,61]$.

\section{Radioisotope dosage}

Both $\mathrm{Sr}^{89}$ chloride and $\mathrm{Sm}^{153}$ tetraphosphonate are administered intravenously in a one-time injection. In the case of $\mathrm{Sr}^{89}$ a standard dose of $150 \mathrm{MBq}-4 \mathrm{mCi}$ is typically administered or is calculated as follows: from 1.1 to $3.0 \mathrm{MBq} / \mathrm{kg}$ of body mass. As regards Sm153, the starting therapeutic dose is calculated as follows: $37 \mathrm{MBq} / \mathrm{kg}$ of body mass. The most common indications for reduction of the calculated dose by $25-50 \%$ are limit haematological parameters and signs of moderate renal failure. Radioisotope therapy might be repeated many times, providing its effect is satisfactory and no side effects are observed. Typically, a patient is not qualified for next dose if visible side effects were seen or no improvement was observed. However, in the latter case a change of the applied isotope could be considered, especially from $\mathrm{Sr}^{89}$ to $\mathrm{Sm}^{153}$. According to current Polish regulations,
Table 6. Effectiveness of isotope monotherapy and monotherapy combined with local radiotherapy

\begin{tabular}{lcc}
\hline Treatment effect & $\begin{array}{c}\text { Isotope } \\
\text { monotherapy }\end{array}$ & $\begin{array}{c}\text { Isotope therapy } \\
\text { with local radiotherapy }\end{array}$ \\
\hline Total pain relief & $30-40 \%$ & $50-65 \%$ \\
Partial pain relief & $40-50 \%$ & $20-30 \%$ \\
Unsatisfactory effect & $20 \%$ & $15-20 \%$ \\
\hline
\end{tabular}

bone metastases therapy with the use of $\mathrm{Sr}^{89}$ and $\mathrm{Sm}^{153}$ might be conducted in ambulatory conditions in nuclear medicine departments that meet certain conditions. Due to the nature of the applied isotopes, the patient does not pose a direct threat to their surroundings, providing that certain precautions are undertaken $[47,48]$.

\section{Treatment effectiveness}

Treatment effectiveness depends on a few factors [51-56]:

1. Quantity, localization, and size of metastatic lesions in the bone. The more foci, the greater the lesion diameter and presence of potential cracks or fractures (especially vertebral), the greater the component of neuropathic pain, the poorer the treatment effect.

2. Scheme of treatment (monotherapy or therapy combined with radiotherapy and/or bisphosphonates) and the size of administered dose (Table 6).

\section{Post-therapeutic patient control and potential undesirable effects}

The first control after the treatment should take place after approximately 2 weeks, the second between the $4^{\text {th }}$ and $6^{\text {th }}$ weeks, and the third between the $8^{\text {th }}$ and $12^{\text {th }}$ weeks. The follow up should include evaluation of analgesic effect, neurologic condition control examination (especially in metastases to the spine), and evaluation of haematological parameters (obligatorily blood count with platelets and smear), calcaemia level, and individual evaluation of renal and hepatic parameters as well as neoplastic markers. The following potential undesirable effects should be taken into consideration:

- increased pain symptoms (in 10-20\% of patients "flare syndrome" might develop), especially in the cases of presence of neuropathic pain (nerve compression etc.) - prophylactics or reduction of the said complaints is possible by short use of glycocorticosteroids (e.g. dexamethasone $4 \mathrm{mg} / \mathrm{a}$ day in a dose decreasing by $1 \mathrm{mg}$ every 5-7 days). Prior to glycocorticosteroid administration a history should be taken as regards the presence of direct and indirect contraindications for this type of therapy, and the patient should be informed about possible undesirable effects of the drug;

- temporary impediment of bone marrow function. A decrease in the number of platelets and leukocytes is observed most commonly between the $2^{\text {nd }}$ and $8^{\text {th }}$ weeks after administration of radioisotope dose and typically does not exceed $30-50 \%$ of starting parameters. Very rarely is it necessary to hospitalize patients due to myelotoxic complications in radioisotope therapy and with proper qualification. Such a necessity is pro- 
portional to the large number and massiveness of metastatic lesions diagnosed in the skeletal system. This risk increases in the case of previous treatment of high myelotoxicity probability as well as numerous clinical signs of neoplastic infiltrate within bone marrow;

- hypercalcaemia. It develops rarely. An increase in calcium concentration is connected with osteolysis in metastatic foci and is typically short and easy to control with bisphosphonates;

- pathologic fractures. Intensive post-therapeutic osteolysis of large metastatic foci that were earlier connected with high risk of fracture might lead (especially in patients who showed pain relief and sudden increase of life activity) to pathologic fractures. Such probability is more common in mixed metastases patients or those with clear domination of osteolysis localized in the spine, pelvis, or femora. In such cases standard combination of isotopic therapy with bisphosphonate treatment might be particularly beneficial [9, 57-59].

\section{Economic aspect of radioisotope therapy}

The cost of pain treatment with the use of radioisotopes is less than half the cost of conservative treatment. As regards isotope therapy patients, no clear statistical data regarding lengthening of life can be found. However, these patients report improved life quality, and a lower number of both pathologic fractures and clinical circumstances requiring hospitalization is observed $[45,61-63]$.

\section{Conclusions}

1. Radioisotopes are effective drugs in the treatment of osteoblastic and mixed bone metastases, in monotherapy and in combination with radiotherapy.

2. Radioisotope treatment in the case of diagnosing bone metastases might be applied even prior to development of clinical symptoms, which reduces the number of new pain sites and the risk of pathologic fractures.

3. Radioisotope treatment considerably raises quality of life and reduces both pain and necessity of administering analgesics.

4. Radioisotope therapy causes statistically significant reduction of treatment costs in bone metastases patients.

\section{References}

1. Drosik K, Krzakowski M, Jarosz J et al. Bisfosfoniany w zapobieganiu i kontroli zdarzeń kostnych u chorych z przerzutami nowotworów złośliwych do kości. Onkol Prakt Klin 2006; 2: 152-162.

2. Casimiro S, Guise TA, Chirgwin J. The critical role of the bone microenvironment in cancer metastases. Mol Cell Endocrinol 2009; 310: 71-81.

3. Lamoureux F, Richard P, Wittrant Y, Battaglia S, Pilet P. Therapeutic relevance of osteoprotegerin gen therapy in osteosarcoma: blockade of the vicious cycle between tumor cell proliferation and bone resorption. Cancer Res 2007; 67: 7308-7318.

4. Tanaka S, Nakamura K, Takahasi N, Suda T. Role of RANKL in physiological and pathological bone resorption anf therapeutics targeting the RANKL-RANK signaling system. Immunol Rev 2005; 208 : $30-49$
5. Stanisławski M, Kmieć Z. Udział RANK, RANKL i OPG w osteolizie towarzyszącej nowotworom. Postępy Hig Med Dośw 2009; 63 234-241.

6. Xing L. Regulation of osteoclast precursors in inflammatory bone loss. Curr Opin Investig Drugs 2009; 10: 1195-1203.

7. Janjan N. Bone metastases: approaches to management. Semin Oncol 2001; 28 (4 suppl 11): 28-34

8. Galasko C. Incidence and distribution of skeletal metastases. Clin Orthop 1986; 210: 14-22

9. Coleman R. Clinical features of metastatic bone disease and risk of skeletal morbidity. Clin Cancer Res 2006; 12 (suppl 20): 6243-6249.

10. Nielsen OS, Munro AJ, Tannock IF. Bone metastases: pathophysiology and management policy J Clin Oncol 1991; 3: 509-524.

11. Yamashita K, Ueda T, Komatsubara Y, Koyama H, Inaji H, Yonenobu K Ono K. Breast cancer with bone-only metastases. Visceral metastases-free rate in relation to anatomic distribution of bone metastases. Cancer 1991; 68: 634-637.

12. Soloway MS, Hardeman SW, Hickey D, Raymond J, Todd B, Soloway S, Moinuddin M. Stratification of patients with metastatic prostate cancer based on extent of disease on initial bone scan. Cancer 1988; 61: 195-202.

13. Blake GM, Zivanovic MA, McEwan AJ, Ackery DM. Sr-89 therapy: strontium kinetics in disseminated carcinoma of the prostate. Eur J Nucl Med 1986; 12: 447-454.

14. Noguchi M, Kikuchi $H$, Ishibashi M, Noda S. Percentage of the positive area of bone metastasis is an independent predictor of disease death in advanced prostate cancer. Br J Cancer 2003; 88: 195-201.

15. Imbriaco M, Larson SM, Yeung HW et al. A new parameter for measuring metastatic bone involvement by prostate cancer: the bone scan index. Clin Cancer Res 1998; 4: 1765-1772.

16. Polascik TJ. Bisphosphonates in oncology: evidence for the prevention of skeletal events in patients with bone metastases. Drug Des Devel Ther 2009; 3: 27-40

17. Saylor PJ, Smith MR. Bone health and prostate cancer. Prostate Cance Prostatic Dis 2010; 13: 20-27.

18. Srour JF, Braza J, Smetana GW. A pain in the bone. J Hosp Med 2010 5: 107-112.

19. Mundy GR. Metastasis to bone: causes, consequences and therapeutic opportunities. Nat Rev Cancer 2002; 2: 584-593.

20. Coleman RE. Skeletal complications of malignancy. Cancer 1997; 80 (supl 8): 1588-1594.

21. Silberstein EB. Advances in our understanding of the treatment of painful metastases. J Nucl Med 2000; 41: 655-657.

22. Dotan ZA. Bone imaging in prostate cancer. Nat Clin Pract Urol 2008; 5: 434-444.

23. Venkitaraman R, Cook GJ, Dearnaley DP et al. Whole-body mag netic resonance imaging in the detection of skeletal metastases in patients with prostate cancer. J Med Imaging Radiat Oncol 2009; 53: 241-247.

24. Kawaguchi M, Tateishi U, Shizukuishi K, Suzuki A, Inoue T. 18F-fluoride uptake in bone metastasis: morphologic and metabolic analysis on integrated PET/CT. Ann Nucl Med 2010; 24: 241-247.

25. Cascini G, Falcone C, Greco C, Bertucci B, Cipullo S, Tamburrini O Whole-body magnetic resonance imaging for detecting bone metastases: comparison with bone scintigraphy. Radiol Med 2008; 113 1157-1170.

26. Gutzeit A, Doert A, Froehlich JM et al. Comparison of diffusion-weighted whole body MRI and skeletal scintigraphy for the detection of bone metastases in patients with prostate or breast carcinoma. Skeletal Radiol 2009; 8: 27-40.

27. Beheshti M, Langsteger W, Fogelman I. Prostate cancer: role of SPECT and PET in imaging bone metastases. Semin Nucl Med 2009; 39 396-407. 
28. Ketelsen D, Röthke M, Aschoff P et al. Detection of bone metastasis of prostate cancer - comparison of whole-body MRI and bone scintigraphy. Rofo 2008; 180: 746-752.

29. Papathanassiou D, Bruna-Muraille C, Jouannaud C, Gagneux-Lemoussu L, Eschard JP, Liehn JC. Single-photon emission computed tomography combined with computed tomography (SPECT/CT) in bone diseases. Joint Bone Spine 2009; 76: 474-480

30. Sadik M, Hamadeh I, Nordblom $P$ et al. Computer-assisted interpretation of planar whole-body bone scans. J Nucl Med 2008; 49 1958-1965.

31. Litwiniuk M, Kopczyński Z. Przydatność markerów obrotu kostnego w rozpoznawaniu i monitorowaniu przebiegu leczenia przerzutów nowotworowych do kości. Współcz Onkol 2002; 6: 384-390.

32. Ozu C, Nakashima J, Horiguchi Y, Oya M, Ohigashi T, Murai M Prediction of bone metastases by combination of tartrate-resistant acid phosphatase, alkaline phosphatase and prostate specific antigen in patients with prostate cancer. Int J Urol 2008; 15: 419-422.

33. Zissimopoulos A, Stellos K, Matthaios D et al Type I collagen biomarkers in the diagnosis of bone metastases in breast cancer, lung cancer urinary bladder cancer and prostate cancer. Comparison to CEA, CA 15-3, PSA and bone scintigraphy. J Buon 2009; 14: 463-472.

34. Mc Ewan AJ. Use of radionuclides for the palliation of bone metastases Semin Radiat Oncol 2000; 10: 103-114

35. Fang N, Li Y, Xu YS et al. Serum concentrations of II-2 and TNF-alpha in patients with painful bone metastases: correlation with responses to 89SrCl2 therapy. J Nucl Med 2006; 47: 242-246.

36. Lass P. Radioterapia izotopowa przerzutów nowotworowych do kośćca Współczesna Onkologia 2001; 5: 185-187

37. Liepe K, Runge R, Kotzerke J. Systemic radionuclide therapy in pain pallation. Am J Hosp Palliat Care 2005; 22: 457-464.

38. Nilsson S, Larsen RH, Fossa SD et al. First clinical experience with alpha-emitting radium-223 in the treatment of skeletal metastases. Clin Cancer Res 2005; 11: 4451-4459.

39. Bruland OS, Nilsson S, Fisher DR, Larsen RH. High-linear energy transfer irradiation targeted to skeletal metastases by the alpha-emitter 223Ra: adjuvant or alternative to conventional modalities? Clin Cancer Res 2006; 12 (20 Pt 2): 6250-6257.

40. Kraeber-Bodere F, Campion L. Treatment of bone metastases of prostate cancer with strontium-89 chloride: efficacy in relation to the degree of bone involvement Eur J Nucl Med 2000; 27 : 1487-1493.

41. O 'Donoghue JA, Bardies M, Wheldon TE. Relationships between tumor size and curability for uniformly targeted therapy with beta-emitting radionuclides J Nucl Med 1995; 36: 1902-1909.

42. Anderson P, Nunez R. Samarium lexidronam (153Sm-EDTMP): skeletal radiation for osteoblastic bone metastases and osteosarcoma. Expert Rev Anticancer Ther 2007; 7: 1517-1527.

43. Dafermou A, Colamussi P. A multicentre observational study of radionuclide therapy in patients with painful bone metastases of prostate cancer Eur J Nucl Med 2001; 28: 788-798.

44. Serafini AN. Palliation of pain associated with metastatic bone cancer using samarium-153 lexidronam; a double-blind placebo-controlled clinical trial. J Clin Oncol 1998; 16: 1574-1581.

45. Liepe K, Runge R, Kotzerke J. The benefit of bone-seeking radiopharmaceuticals in the treatment of metastatic bone pain. $\mathrm{J}$ Cancer Res Clin Oncol 2005; 131: 60-66.

46. Pinski J, Dorff TB. Prostate cancer metastases to bone: pathophysiology, pain management, and the promise of targeted therapy. Eur $J$ Cancer 2005; 41: 932-940.

47. Kinoshita A. ESR dosimetry of $89 \mathrm{Sr}$ and $153 \mathrm{Sm}$ in bone Appl Radiat Isot 2001; 54: 269-274.
48. Żórawska A, Kowalska A. Ocena narażenia na działanie promieniowania jonizującego personelu i współmieszkańców od pacjentów poddanych paliatywnemu leczeniu preparatem Quadramet zawierającym Sm-153. Współcz Onkol 2002; 6: 522-525.

49. Lam MG, de Klerk JM, Zonnenberg BA. Treatment of painful bone metastases in hormone-refractory prostate cancer with zoledronic acid and samarium-153 ethylenediaminetetramethylphosphonic acid combined. J Palliat Med 2009; 12: 649-651.

50. Lam MG, Dahmane A, Stevens WH, van Rijk PP, de Klerk JM, Zonnenberg BA. Combined use of zoledronic acid and 153Sm-EDTMP in hormone-refractory prostate cancer patients with bone metastases. Eur J Nucl Med Mol Imaging 2008; 35: 756-765

51. Bączyk M, Milecki P, Martenka P, Sowiński J. Efficacy of samarium 153 and strontium 89 treatment for bone metastases in prostate cancer patients: monotherapy vs. treatment combined with external beam radiotherapy. Preliminary report. Rep Pract Oncol Radiother 2007; 12 211-216.

52. Djabełek-Maciaś M, Wiśniewska I, Ochman M, Kołodziejczyk A, Zebrowski J, Piwkowski P. The effects of radioisotope therapy and radiotherapy in subjects with breast cancer with bone metastases. Nucl Med Rev Cent East Eur 2006; 9: 138-143.

53. Oosterhof GO, Roberts JT, de Reijke TM et al. Strontium(89)chloride versus palliative local field radiotherapy in patients with hormonal escaped prostate cancer: a phase III study of the European Organisation for Research and Treatment of Cancer, Genitourinary Group. Eur Urol 2003; 44: 519-526.

54. Ron IG, Stav O, Vishne $T$ et al. The correlation between palliation of bone pain by intravenous strontium-89 and external beam radiation to linked field in patients with osteoblastic bone metastases. Am J Clin Oncol 2004; 27: 500-504

55. Porter AT, McEvan AJ. Results of a randomised Phase III trial to evaluate the efficacy of strontium 89 adjuvant to local field external beam irradiation in the management of endocrine resistant metastatic prostate cancer. Int J Radiation Oncol Biol Phys 1993; 25: 805-813.

56. Quilty PM, Kirk D, Bolger JJ. A comparison of the palliative effects of strontium 89 and external beam radiotherapy in metastatic prostate cancer. Radiotherapy and Oncology 1994; 31: 33-40.

57. Bączyk M, Bączyk E, Sowiński J. Wstępne wyniki skojarzonego zastosowania radioizotopów i bisfosfonianów w leczeniu bólu związanego z osteoblastyczno-osteolitycznymi przerzutami raka gruczołu piersiowego do kości. Ortop Traum Rehab 2003; 5: 234-237.

58. Yuen KK, Shelley M, Sze WM, Wilt T, Mason MD. Bisphosphonates for advanced prostate cancer. Cochrane Database Syst Rev 2006; 18 CD006250

59. Pavlakis N, Stockler M. Bisphosphonates for breast cancer. Cochrane Database Syst Rev 2002; 1: CD003474.

60. Wang RF, Zhang CL, Zhu SL, Zhu M. A comparative study of samarium-153-ethylenediaminetetramethylene phosphonic acid with pamidronate disodium in the treatment of patients with painful metastatic bone cancer. Med Princ Pract 2003; 12: 97-101

61. Bączyk M, Czepczyński R, Milecki P, Pisarek M, Oleksa R, Sowiński J. 89Sr versus 153Sm-EDTMP: Comparison of treatment efficacy of painful bone metastases in prostate and breast carcinoma. Nucl Med Commun 2007; 28: 245-250.

62. Robinson RG. Strontium 89: Treatment results and kinetics in patients with painful metastatic prostate and breast cancer in bone. Radiographics 1989; 9: 271-278

63. Velasco Latras M, Carreras Coderch L, Antonanzas Villar F et al Cost-effectiveness analysis of samario-153 (Quadramet) for the treatment of patients with prostate cancer and bone metastases. Clin Transl Oncol 2005; 7: 198-204. 